\title{
Using an Interactive Computer System to Support the Task of Building the Notions of Ratio and Proportion
}

\author{
Elena Fabiola Ruiz Ledesma
}

Escuela Superior de Cómputo del Instituto Politécnico Nacional, Departamento de Posgrado, México.

Email: elen_fruiz@yahoo.com.mx

Received February $27^{\text {th }}, 2010$; revised July $18^{\text {th }}, 2010$; accepted July $25^{\text {th }}, 2010$.

\begin{abstract}
This article describes the design and general outcome of applying a computer system that includes interactive activities to the topics of ratio and proportion. The work was undertaken with Mexican students attending primary school grade six (11 year olds). In designing the activities, our work was based on the studies of researchers who have focused on such topics, as well as on the work of researchers in the field of computer sciences and education technology. Support of the activities designed is found in psycho-pedagogy, in knowledge of mathematics and in the fields of computer sciences and education technology.
\end{abstract}

Keywords: Ratio, Proportion, Interactive Activities

\section{Introduction}

There is little doubt of just how important it is that students attending basic education classes develop cognitive structures in the area of mathematics, structures that provide them with the basis needed to successfully meet the academic demands of the next school system level. Hence development of software for basic education in mathematics becomes just as significant in the current Mexican context because incursion of computers into that educational level raises the need to analyze which pedagogical strategies recommended by Mexican researchers to teach the concepts of ratio and proportion can be incorporated into an educational software system, and precisely how that should be done.

Consequently the authors of this article have focused their attention on supporting the task of building the notions of ratio and proportion. And in doing so, they have developed a computer system that uses technology to carry out interactive activities.

In this article, the authors introduce a teaching proposal developed in a computer system with interactive activities that make use of technology. The design of the proposal activities was based on a prior study undertaken by Ruiz, [1] with students who course six grade of primary school and that deals with the topics of ratio and proportion. These topics were selected in view of the fact that their instruction is begun in primary school and that they serve as the basis for subsequent concepts, such as those of direct proportional variation or linear function.

\section{Portrayal of the Problem}

To identify whether the ratio and proportion teaching activities designed through a computer system enable the 11 year-old student to build notions or ratio and proportion, developing said student's qualitative proportional thought and aiding him/her to recover the sense of his qualitative proportional thought.

Qualitative proportional thought is supported by linguistic recognition, creating comparison categories such as large or small. Qualitative thought also includes things intuitive that are based on experience and that are empirical, and things perceptual that are supported by the senses.

Qualitative proportional thought refers to activities that enable students to count measure and employ quantities in procedures.

\section{Theoretical Basis}

\subsection{On Ratio and Proportion}

According to Piaget [2] one can see in 11 and 12 year old subjects the presence of the notion of proportion in different areas, notions such as: spatial proportions (like 
figures), the relation between the weights and length of arms on a scale, probabilities, etc. [3], also states, based on his experiments, that children acquire their qualitative identity before their quantitative conservation, and further distinguishes between qualitative comparisons and true quantification.

In fact for Piaget the notion of proportion always begins qualitatively and logically prior to being structured from a quantitative standpoint. He stresses that in order for a student to develop his / her qualitative proportional thought that student must necessarily begin with the notions of enlargement and reduction, following the idea of a photocopier or scale drawing, assuming that at a very early age the student is able to recognize what is proportional.

According to Piaget and Inhelder [3] after the student develops his / her perceptual ability, an ordering takes place by way of comparisons, which can be seen when students use phrases the likes of "larger than..." and "smaller than..." and which are known as verbal categories. In this sense Piaget says that during the transition from things qualitative to things quantitative, the idea of order appears without a quantity having yet emerged, an event that Piaget calls intensive quantifications.

Subsequently when students use measurements to make comparisons they first confront parts of the object and superimpose one figure on top of another and afterward use a measuring instrument, be that a conventional instrument or not. Freudenthal [4] states that comparisons make it possible to measure and measurement is shown by way of two modes: direct and indirect. The direct mode of comparing is when an object is superimposed onto another object, while the indirect mode is when there are two objects (A and B) and a third element to compare (C).

With respect to the emphasis that should be placed on early education of ratio and proportion, Streefland [5-7], states that the point of departure should be qualitative levels of ratio and proportion recognition and that use should be made of didactic resources that foster development of perceptual patterns in support of the corresponding quantification processes.

The didactics of mathematics are referred to as an essential activity in teaching ratio and proportion, as is the importance of didactic tools developed by the designer. Freudenthal's Didactic Phenomenology [4] is particularly mentioned, together with other background considered in order to attain a realistic building of mathematics.

Freudenthal indicates that comprehension of ratio can be guided and deepened by way of visualizations. He moreover states that such visualizations can be illustrated by way of detailed constructions in which the drawings are differentiated and in which the drawings depict which points of the original and image actually coincide. An example of the foregoing is in two contiguous figures one of which is an enlargement or reduction of the other, and in which the same linear ratio can be established in each segment of the figure. Freudenthal suggests that when working with the ratio of longitudes, flat figures is used as a means of representation because of their global expressiveness, in the sense that a student's qualitative and quantitative comprehension is facilitated by visual perception.

Ruiz and Valdemoros [8] found that the students she worked with presented different difficulties, specified as: a) The students' qualitative thought dealing with proportionality has not been exploited to the utmost, which was observed when they demonstrated that they were centered on one of the dimensions of the figures they had been asked to reduce or expand; b) In some students, things qualitative are barely raised as an introduction to things quantitative, given that in the linguistic categories detected among them, one found the following: "it is larger than...", "it is smaller than...", which reflects a certain understanding of proportion; yet among these same students one did not find other categories through which they showed a greater understanding of the idea of proportion; c) They appeared confused when establishing relations between quantities, which is why is became necessary to emphasize that in order to reach the notion of ratio.

\subsection{Technological Elements}

Lim [9], states that technology makes it possible for teachers to be more flexible thus enabling them to address the different needs of students with varying levels of capabilities - all of whom may be sharing one single classroom- by using software that can be adapted to the teaching and to the particular conditions of each student or group. Technology makes it possible for teachers to divide their groups of students into teams and to work with each one at their own pace. What is more, technology can make it possible for the students to determine the pace at which they feel comfortable working.

Some research has been undertaken for the purpose of finding out if usage of a Web-based environment benefits learning. The study carried out by Galbraith and Haines [10] shows that students who use a computer in their daily mathematics learning enjoy mathematics. They like the flexibility provided by the computer and spend a great deal of time at the computer to complete a task, and enjoy trying out new ideas. The researchers also concluded that Web-based applications increase levels of confidence, motivation and interaction.

Nguyen and Kulm [11], Combs [12], Gourash [13] and 
Engelbrecht and Harding [14,15], point out that usage of computers in educational terms enables students to find the meaning of what they are doing in that their ability to discover is developed and they are able to delve deeper.

Working with the points mentioned by the researcher in the previous paragraphs, Table 1 depicts a specification of the indicators that refer to ratio and proportion, as well as to the didactic actions associated to those indicators.

\section{Methodology}

Under this heading the authors of this article have included the subjects with whom work was undertaken, the elements of the computer system used to carry out didactic activities and the didactic activities themselves.

\section{Subjects}

The research was carried out with a sample of 29 students all in the same grade six class of a primary school in Mexico City, to whom the activities designed were applied.

\section{Sequence of activities and their presentation in the} computer system

Taken into account in the task of designing the sequence of activities are the didactic actions specified in the theoretical framework, the computer activities, as well as the theoretical elements entailed in the concepts of ratio and proportion.

Activity 1. Choose the reduced or enlarged figure of the figure provided, by way of visualization.

This activity is based on ideas of "reduction" and "enlargement" supported by models of the scale and photocopier drawings-type experiment, using things perceptual and observation.

This was used as the point of departure in view of that indicated by Piaget, [12], Streefland, [5-7] and Ruiz y Valdemoros [8], regarding the point that early instruction on ratio and proportion needs to begin with qualitative levels of that learning, which is why activities that do not require use of quantities for solution of the activities are first used.

Table 1. Objectives, indicators and didactic actions of the concepts of ratio and proportion.

\begin{tabular}{|c|c|c|c|}
\hline Concepts & Objectives & Indicator & Didactic Actions \\
\hline \multirow{2}{*}{$\begin{array}{l}\text { Ratio: } \\
\text { Relation between } \\
\text { two magnitudes } \\
\text { expressed } \\
\text { through a quo- } \\
\text { tient }\end{array}$} & Intuitively establish ratios & Compare & $\begin{array}{l}\text { Superimpose figures } \\
\text { Use verbal categories such as "one side fits twice in the other } \\
\text { side" or "one side is one third of the other side" }\end{array}$ \\
\hline & Explicitly establish ratios & $\begin{array}{l}\text { Express the ratio in the } \\
\text { form of a fraction }\end{array}$ & $\begin{array}{l}\text { Count the sides of a square (in a grid) } \\
\text { Use a table } \\
\text { Count the sides of a square and write out the ratio as a fraction. }\end{array}$ \\
\hline \multirow{3}{*}{$\begin{array}{l}\text { Proportion: Re- } \\
\text { lation of ratios or } \\
\text { the equivalence } \\
\text { of two or more } \\
\text { ratios }\end{array}$} & $\begin{array}{l}\text { Qualitative proportional } \\
\text { thought }\end{array}$ & $\begin{array}{l}\text {-Visualize } \\
\text {-Use linguistic } \\
\text { expressions }\end{array}$ & $\begin{array}{l}\text { Choose reduced or expanded figures. } \\
\text { Enlarge and reduce figures. } \\
\text { Use verbal categories, such as "larger than” or "smaller than” }\end{array}$ \\
\hline & $\begin{array}{l}\text { Transition from qualitative } \\
\text { to quantitative propor- } \\
\text { tional thought }\end{array}$ & $\begin{array}{l}\text {-Compare } \\
\text {-Measure indirectly }\end{array}$ & $\begin{array}{l}\text { Superimpose figures } \\
\text { Count sides in the squares of a grid }\end{array}$ \\
\hline & $\begin{array}{l}\text { Quantitative proportional } \\
\text { thought }\end{array}$ & $\begin{array}{l}\text {-Measure directly } \\
\text {-Use the rule of three or } \\
\text { of the excluded third }\end{array}$ & $\begin{array}{l}\text { Measure using a conventional instrument } \\
\text { Use the table } \\
\text { Carry out number operations }\end{array}$ \\
\hline
\end{tabular}

Table 2. Contains the relation existing between Table 1 activities and the actions to be undertaken on the computer.

\begin{tabular}{ll}
\hline Didactic Actions & Actions on the Computer \\
\hline $\begin{array}{l}\text { Superimpose figures } \\
\text { Use verbal categories }\end{array}$ & $\begin{array}{l}\text { Drag the mouse } \\
\text { Count the sides of a square } \\
\text { (in a grid) }\end{array}$ \\
$\begin{array}{l}\text { Choose reduced or enlarged } \\
\text { figures }\end{array}$ & Use a pencil, like in Paint \\
$\begin{array}{l}\text { Expand or reduce figures } \\
\text { Measure using a conventional } \\
\text { instrument }\end{array}$ & Click on the option \\
Use the table & Use ruler \\
Carry out number operations & $\begin{array}{l}\text { Table to the filled in by the } \\
\text { student }\end{array}$ \\
\hline
\end{tabular}

Consideration has furthermore been given to Freudenthal's points that deal with guiding and deepening comprehension of ratio through visualizations.

By the same token the figures designed in the computer system relate to the knowledge possessed by 11 year old children, to whom the figures are aimed. Examples of the foregoing could be a boat, a bus, a star, a dog, albeit all drawn in straight line segments.

\section{How the concepts appear in the computer system}

Shown are four similar figures, all of which have small differences. One of the four figures is also depicted in a double or triple linear amplification or reduced by half or to a third of the linear size. The user is asked to choose among the four figures and find the figure that is a reduced version of the original. (See Figure 1). 


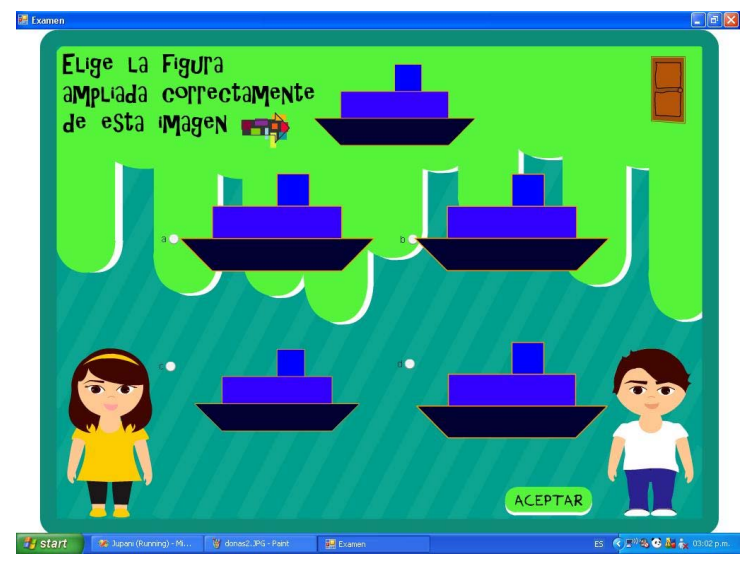

Figure 1. Source: Created by the authors.

After having chosen one of the figures, the choice is then analyzed and an answer is immediately provided bearing the result of the analysis. The user is asked if he / she wants to try again, the answer is received and, depending on that answer, the exercise is either restarted or work is continued with the next exercise.

Activity 2. Choose the figure that is a reduction of amplification of the figure provided, by way of comparison.

\section{Case 1 Superimpose one figure over another}

Superimposition of one figure on top of another enables subjects to recognize relations of similarity among the figures in intuitive terms.

The action of comparing figures is the beginning of measurement, yet without using a conventional instrument since it is achieved by superimposing the figures just as specified by Freudenthal, 1983.

How the activity appears in the computer system?

The student has the option of using his / her mouse to drag any of the four figures in order to place the figure on top of the original and review the result, by way of visualization, to see if the figure is an enlargement or reduction on all sides by the same amount. See Figure 2.

\section{Case 2 Use of a grid}

The transition from qualitative to quantitative proportional thought is achieved by using the grid [1] Counting is used and the measurement unit is one side of a square in the grid in which the figures are portrayed.

The result of the process of counting the sides of the figures is used in order to establish quotient relations with the results obtained, that is to say ratios. This is also done for the purpose of establishing relations of equivalence between two ratios or proportions.

\section{How the activity appears in the computer system}

The student is presented with a figure on a grid, as well as another empty grid in which he / she can draw and use the grid itself as a means of support. The student

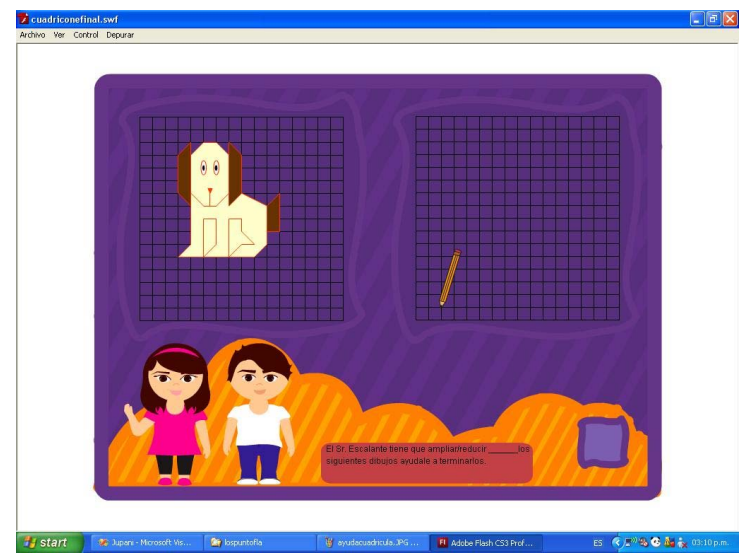

Figure 2. Source: Created by the authors.

is asked to draw the figure at double or half or one third, etc., of its original size (See Figure 2). The drawing in the first grid is a means of support, used to compare with the drawing done by the student. The student is told whether his / her answer is correct and asked if he / she wants to repeat the exercise, and the student decides if he / she wants to repeat the exercise or go on to the next one.

\section{Activity 3. Use of the table}

The table was used as a means of representation in order to determine internal and external ratios Freudenthal [4]. The students work with proportional variation problems and obtainment of the quantities is not only achieved through use of the operator, but also by establishing relations among ratios.

Finally, work was done on equivalence relations as a proportionality relation.

\section{Outcomes of the didactic activities}

\section{Activity 1. Choose the figure using visualization}

Eleven of 29 students used observation to choose the reduced figure. Whereas the remaining 18 decided to compare the figures by superimposing one figure over the others. They used the mouse to drag the figure to see if it was, from the side or width, double, half or one third of the original. All of this was commented upon during the session; and furthermore coincides with Freudenthal [4]. If the figure in question was a circumference, the students compared the radii or the diameters. Consequently all of the students were able to determine that the answer was the reduced figure, and each student decided for him / herself whether to drag the figure and superimpose it over the other figure in order to compare them. This student reaction is similar to comments made by Combs [12].

\section{Activity 2. Grid}

Of the entire group of 29 students, 23 were able to draw correctly on the grid figures that were similar to 
those presented to them. The remaining 6 students made two to three attempts before they were successful with the task. The computer system was extremely useful in that it presents the student with the option of working with different figures, thus making for work that is not mechanical. What is more, students are given the opportunity to discover what is taking place.

The work reached the level of recognition of ratios as a comparison by quotient of two quantities. The group worked on notation of ratios in the form of a / b fractions, in which $b$ is a different from 0 .

\section{Activity 3. Use of the table}

Once again of the entire group of 29, 20 students were able to fill in the table correctly. They accomplished this by deciphering the unit value, in the event that it was not provided, while others established ratios by reading them from the table and writing them down in the form of fractions. All students used the calculator, first determining the operations that had to be undertaken; for instance, in Figure 3, reference is made to the case of Luis.

When faced with the activity, this is what Luis did: In the case of Luis, one can see that he establishes rela- tions between two variables, the milk and the chocolate bars. In Freudenthal terms, these are external ratios.

Manuel is another case: What Manual expressed when solving the activity can be seen in Figure 4.

Manuel was asked to provide a conclusion, as follows:

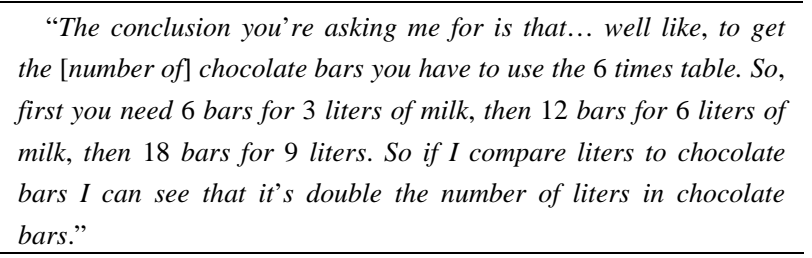

There is indeed food for thought in Manuel's work. Before asking him to provide a conclusion, Manuel had already established relations among the data in one of the columns, the liters of milk column. Freudenthal refers to this as internal ratios.

Usage of the table enabled the students to establish relations between magnitudes of figures, to the point of establishing both internal and external ratios (as per their definition by Freudenthal). Lastly the students were in-

"I saw that 3 fits 2 times into 6, so for 3 liters of milk you need 6 bars of chocolate. In other words, you need double the amount of chocolate bars, so one liter needs two bars, two liters four bars, three liters six bars.

I'll just use the calculator to multiply by two to fill in the data I'm asked for"

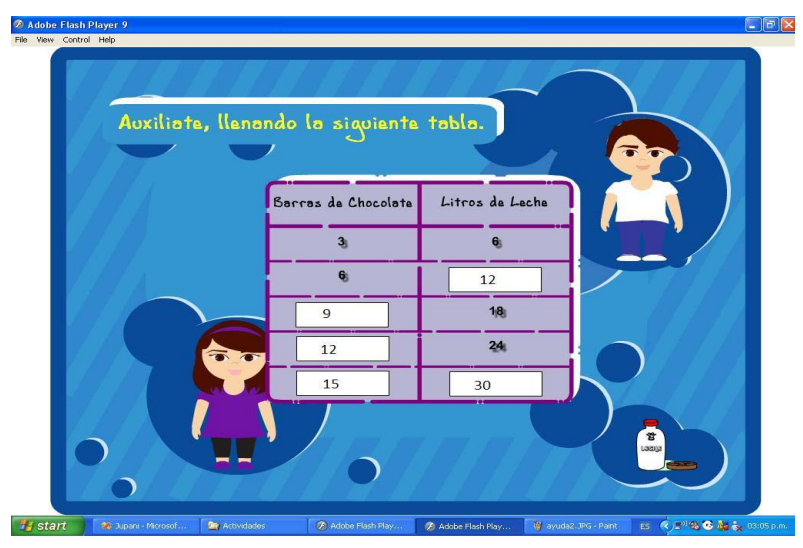

Figure 3. Response provided by Luis in the activity of filling in the table.

\footnotetext{
"I saw how the quantities in the chocolate bars column changed, because they gave us more numbers in that column. I saw that it began with 6 , then there was a blank that I had to fill in, then came the 18 and right after that the 24. I used the calculator to divide 18 by 6 , and it gave me a result of 3 ; then $I$ divided 24 by 6 and it gave me 4. So I took the 6 and multiplied it by 2 and got 12, and that's the value of the second blank, and the last blank in the column is the result I got from 6 times 5, which is 30.”
}

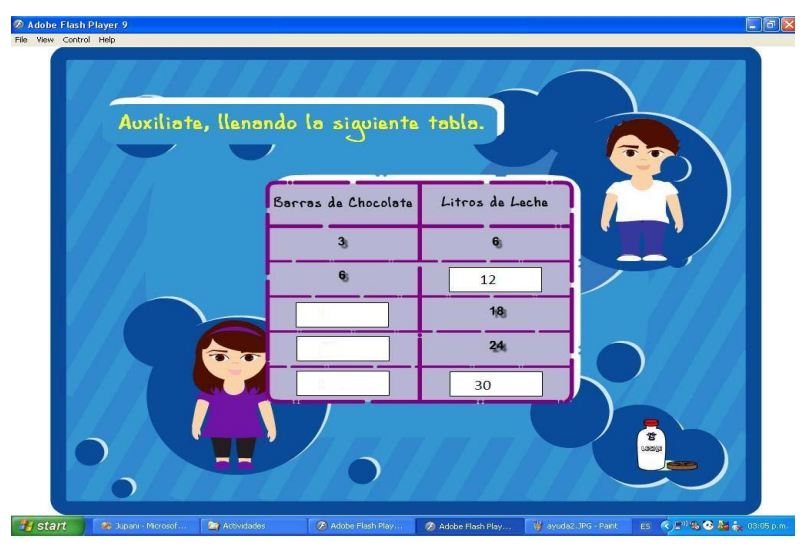

Figure 4. Manuel fills in the table, first filling in the liters of milk column. 
deed able to use the different representation registers drawing, table and things numerical- when they were solving ratio and proportion problems. One is therefore led to point out that work with these interactive activities enabled the students to build the concepts of ratio and proportion, investing them with meaning and sense, rather than just using the algorithm to work on the topics. This is indeed similar to the findings obtained in the studies by Galbraith, P. and Haines, C. [10], Nguyen and Kulm [11], Combs [12] and (Engelbrecht and Harding [15]).

\section{Conclusions}

According to the findings obtained we are in a position to state that the activities designed to support students in the task of consolidating the concepts of ratio and proportion were adequate given that the students demonstrated a great deal of interest when working with the computer system and worked independently to solve the problems. Their teacher did not have to instruct the students to compare one figure with another in order to determine which one was the reduction, rather the students developed that ability thanks to the activities proposed in the system. The foregoing leads one to infer that the students were able to develop both their qualitative and quantitative proportional thought; they showed a good deal of freedom in dragging the mouse, using the grid and filling in the table, activities for which there was no need for their teacher to give them instructions. Working in this manner moreover enabled the students to develop visually and perceptually, in other words they were able to further develop aspects that constitute their qualitative proportional thought.

Use of the table made it possible for the students to establish relations among figure magnitudes, establishing internal and external ratios (as defined by Freudenthal). Finally the students were able to use the different registers of representation (the drawing, the table and things numerical) when solving ratio and proportion problems, which enables the authors of this article to point out that working with interactive activities made it possible for the students to build the concepts of ratio and proportion, and imbue those concepts with meaning and sense rather than simply using the algorithm to work on the topics. This is quite similar to the findings obtained in the studies undertaken by Galbraith, P. and Haines, C., Nguyen and Kulm, (Combs, and (Engelbrecht and Harding, The computer system made it possible for the students using it to develop skills that were not developed by all of the other students in their group using pencil and paper and the blackboard.

\section{REFERENCES}

[1] E. F. Ruiz, "Study Of Solving Strategies and Proposal for the Teaching of Ratio and Proportion," Proceedings of the 22nd Annual Meeting North American Chapter of the International Group for the Psychology of Mathematics Education, Vol. 2, 2000, pp. 395-396.

[2] J. Piaget, "Psicología del Niño,” Madrid: Ediciones Morata, 1978, pp. 131-150.

[3] J. E. Piaget and B. Inhelder, "Las Operaciones Intelectuales y su Desarrollo, Lecturas en Psicología del niño, I. Madrid, 1978, pp. 70-119.

[4] H. Freudenthal, "Didactical Phenomenology of Mathematical Structures,” D. Reidel Publishing Company, Holland, 1983, pp. 178-209.

[5] L. Streefland, "Search for the Roots of Ratio: Some thought on the Long Term Learning Process," Educational Studies in Mathematics, Vol. 15, No. 3. 1984, pp. 327-348.

[6] L. Streefland, "Fractions in Realistic Mathematics Education,” Tesis Doctoral Publicada Por la Kluwer Academic Publishers, Netherlands, 1991.

[7] L. Streefland, "The Design of a Mathematics Course a Theoretical Reflection,” Educational Studies in Mathematics, Vol. 25, No. 1/2, 1993, pp. 109-135.

[8] E. F. Ruiz and M. Valdemoros, "Concepts of Ratio and Proportion in Basic Level Students: Case Study," Proceedings of the 24th Annual Meeting of the North American Chapter of the International Group for the Psychology of Mathematics Education, Vol. 4, 2002, pp. 16511657.

[9] C. K. Lim, “Computer Self-Efficacy, “Academic SelfConcept and Other Predictors of Satisfaction and Future Participation of Adult Distance Learners," American Journal of Distance Education, Vol. 15, No. 2, 2001, pp, 41-51.

[10] P. Galbraith and C. Haines, "Disentangling the Nexus: Attitudes to Mathematics and Technology in a Computer Learning Environment,” Educational Studies in Mathematics, Vol. 36, 1998, pp. 275-290.

[11] D. M. Nguyen and G. Kulm, "Using Web-Based Practice to Enhance Mathematics Learning and Achievement," Journal of Interactive Online Learning, Vol. 3, No. 3, 2005, pp. 1-16. 